\begin{tabular}{lllllllllllllllllllllllllllllllll}
\hline$R$ & $E$ & $V$ & I & S & T & A & D & E & E & S & T & U & D & I & O & S & I & N & T & E & $R$ & N & A & C & I & O & N & A & L & $E$ & S
\end{tabular}

\title{
¿Tiene América Latina
} un papel propio en la comunidad internacional?*

\author{
Soledad Alvear
}

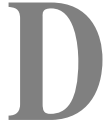

urante el período 1900 a 2002, América Latina experimentó una serie de cambios muy significativos. Desde luego, el número de habitantes aumentó de 70 a 500 millones. A principios del siglo pasado, tres cuartas partes de esa población vivían en zonas rurales, mientras que en la actualidad, dos tercios viven en zonas urbanas. Por otra parte, tres cuartas partes de los habitantes de nuestra región eran analfabetos, comparado con siete de cada ocho personas que saben leer y escribir en nuestros días. La vida se ha transformado radicalmente en cuatro generaciones. Hoy día impera un consenso en torno a la validez de una economía impulsada por la exportación y alimentada por innovaciones tecnológicas, donde el costo social de excluir a los pobres se destaca como un aspecto crucial. En el pasado, sin embargo, la marginación estaba tan arraigada en el tejido social del continente, que no era muy cuestionada.

Pero detrás de estas luces en que puede apreciarse un cambio positivo, hay algunas sombras. Pese a que el ingreso per cápita creció cinco veces durante el siglo pasado, por ejemplo, hoy es más bajo que hace cien años comparado con el de los países industrializados. Se ha levantado una infraestructura moderna y la industria ha crecido hasta alcanzar el $25 \%$ del PIB, pero la proporción del comercio mundial correspondiente a la región se redujo a la mitad. Por este motivo, una de las solicitudes fundamentales de los presidentes de los países de América Latina ha sido la de mayor apertura. En el caso de los países emergentes, durante la Con-

* Conferencia dictada por la autora como parte del Ciclo de Conferencias "América Latina hoy, en 12 preguntas y 120 sugerencias", organizado por el Instituto de Estudios Internacionales de la Universidad de Chile, del 3 al 29 de julio de 2002. 
ferencia de Monterrey ${ }^{1}$ realizada en marzo pasado, el presidente Lagos mencionó explícitamente el deseo de comercio. Ya no estamos pidiendo ayuda, sino comercio y apertura. No queremos el cierre que, lamentablemente, todavía puede verse en algunos países desarrollados.

\section{Pese a la mejora de algunos indicadores sociales, la pobreza sigue afectando a grandes sectores de la población.}

Hay algunos indicadores sociales, como la esperanza de vida y el alfabetismo, que han mejorado en forma espectacular. Sin embargo, la pobreza sigue afectando a grandes sectores de la población latinoamericana. Según estimaciones del Banco Mundial, a fines de los años noventa la proporción del ingreso correspondiente al 20\% más pobre de la región era la más baja de todas las regiones del mundo. Ciertamente, enfrentar el problema de la pobreza constituye el principal reto y desafío que hoy existe en la región. Fue ratificado en la segunda Cumbre Sudamericana realizada durante la semana recién pasada $^{2}$, cuyo objetivo fue identificar los problemas comunes y, fundamentalmente, buscar los mecanismos que identifican a los países de América del Sur para proponer los desafíos siguientes -sobre todo en lo que dice relación con proyectos de infraestructura, energía y comuni- caciones-. Quiero señalar que en esa oportunidad se identificaron alrededor de 300 proyectos de integración en este ámbito y hay algunos muy relevantes, como los corredores bioceánicos, en los cuales Chile ha puesto mucha energía y dedicación. Por ejemplo, el que cubre la ciudad de Cuiabá en Brasil, pasando por Santa Cruz de la Sierra en Bolivia y llegando a Arica, identificado como uno de los sustantivos. Uno de los temas en esta Cumbre fue cómo fundamentar estos proyectos que corresponden a varios países en las solicitudes de crédito a los organismos internacionales, y a través de qué mecanismos podría hacerse.

Luego de esta mirada preliminar respecto de los cambios experimentados en América Latina durante el último siglo, intentaré contestar la pregunta que me formularon para este encuentro - ¿tiene América Latina un papel propio en la comunidad internacional?-y proponer diez sugerencias para evitar el riesgo de la marginalidad en el concierto internacional. Sin duda, se trata de un asunto de gran complejidad, especialmente por la variedad de identidades que cultiva nuestro continente. Porque si bien es cierto aparecemos ante la comunidad internacional como una región con un gran sentido de homogeneidad, debemos reconocer en esta apreciación un cierto sesgo histórico, determinado quizás por la lejanía de nuestro continente de los centros de poder y por el escaso interés que este despierta en los análisis globales sobre rela-

\footnotetext{
${ }^{1}$ Se refiere a la Conferencia Internacional sobre Financiamiento para el Desarrollo, que tuvo lugar del 18 al 22 de marzo de 2001 en Monterrey, México.

${ }^{2}$ Se refiere a la II Cumbre Sudamericana, realizada el 26 de julio de 2002 en Guayaquil, Ecuador.
} 
ciones internacionales. Con la salvedad de Brasil, en América Latina tenemos un idioma común, vivimos procesos históricos muy similares y hemos seguido una ruta de desarrollo más o menos parecida en los distintos países. Pero basta citar estos tres elementos para concluir lo difícil que resulta explicar a quienes no viven la profundidad de esta región del mundo, que detrás de esas unidades hay un sinnúmero de variedades. En otras palabras, hay un aspecto que no debemos desconocer: América Latina es unidad en la diversidad. De lo contrario, nos enfrentamos al riesgo de simplificar el análisis, siendo arrastrados hacia conclusiones que podrían ser imprecisas.

No es fácil entender el fenómeno que nos ocupa, como asimismo, perfilar diez ideas para rescatar a nuestro continente de un proceso de creciente marginalidad. Felizmente, nuestra región se encuentra encadenada en varios aspectos. Primero, el hecho de tener dos lenguajes muy parecidos uno del otro en una región que cuenta con aproximadamente 500 millones de habitantes, constituye un poderoso factor de homogeneidad que ha posibilitado la existencia de formas similares de expresión, transformándose así en un motor de comunicación simple y rico en nuestras relaciones económicas, sociales, históricas y culturales. En segundo lugar, tenemos una historia común. Nuestras similitudes arrancan desde la llegada de los conquistadores, y ese es otro elemento importante que nos ha acompañado a lo largo de la historia. Tercero, los procesos políticos que hemos experimentado en la región también son parecidos entre sí. Hay coincidencia en el transcurso de los procesos de independencia y en el devenir de nuestras propias instituciones en los albores de las naciones jóvenes. Poseemos además una identidad geográfica parecida y fácilmente identificable en el mapa terráqueo, inserta como una gran isla y rodeada por las grandes aguas de los océanos Pacífico y Atlántico, que nos bañan y nos protegen. Todos estos elementos nos marcan y nos definen ante la comunidad internacional.

\section{Nuestras similitudes nos marcan y nos definen ante la comunidad internacional.}

Comparada con otras regiones del mundo, en América Latina hay pocos conflictos armados. Por ese motivo, no dudo en afirmar que nuestro lenguaje matriz es la paz. Eso es lo que busca este continente. Sin embargo, no debemos olvidar que hemos vivido períodos de violencia y tensión que derivaron incluso en lamentables rupturas institucionales y que, además, estos coinciden en la historia de nuestros países. Es como si nuestras instituciones estuvieran insertas en un mismo sistema político histórico, dentro del cual se han nutrido del mismo medio de relaciones culturales y sociales. Dialogar sobre América Latina significa hablar de períodos llenos de contradicciones, siendo algunos de ellos frágiles en términos de convicciones democráticas, y otros opulentos en muestras de constitucionalismo. En todo caso, estoy cierta de la vocación pacifista de nuestra región. Y quiero subrayar esta 
afirmación, pues de ella se desprende una de las sugerencias más importantes que desearía compartir con ustedes: la necesidad de consolidar ese espíritu libertario y la vocación de paz en nuestras propias acciones e interrelaciones cívicas internas.

\section{Debe avanzarse hacia propuestas básicas para articular una dinámica continental viable en un mundo en cambio permanente.}

Finalmente, también debemos reconocer una identidad en los principios que impregnan el quehacer diario en la vida pública de nuestras naciones y que condicionan las expectativas de desarrollo de los pueblos de América Latina. Me parece necesario agregar este elemento al conjunto de ideas que he señalado, pues de lo contrario, no podríamos sumergirnos en lo que hemos querido llamar "el ser" de nuestra región, es decir, nuestra diversidad en la unidad. También debemos aceptar que tenemos nuestras propias individualidades, siendo estas tan gravitantes como las unidades que advertí hace algunos momentos. Este hecho dificulta el análisis global. Aun así, pese a las dificultades que implica tratar de comprender a nuestra región con una mirada única, mi idea es diseñar un conjunto de reflexiones que permitan el acercamiento hacia un horizonte de plena inserción global, no tanto como espectadores, sino como actores activos y con responsabilidades.

No ha sido fácil agrupar en sólo diez sugerencias las propuestas que permitan consolidar un espacio de desarrollo regional alejado de los riesgos de marginación internacional. Pero he intentado delinear diez pasos que sugieran un rumbo hacia el progreso económico, que promuevan el desarrollo social y que impulsen realmente una cultura cívica participativa y moderna, sin marginar de este esfuerzo la viabilidad del modelo. Se trata, entonces, de avanzar hacia un consenso fundamental en ciertas propuestas que yo denominaría básicas para articular una dinámica continental viable en un mundo que, lejos de ser estático, se encuentra en cambio permanente.

\section{UNA GLOBALIZACIÓN DIRIGIDA HACIA EL BIEN COMÚN}

Mi primera sugerencia sería insertar la globalización en las políticas públicas, respetando los valores básicos de la dignidad humana. Esta es una de las propuestas básicas para consolidar un esquema de desarrollo económico perdurable en el tiempo, capaz de consensuar el máximo de visiones de nuestros actores sociales y cuyo fin trascendente sea buscar el bien común, es decir, el mayor desarrollo material y espiritual posible de cada uno de los habitantes de América Latina. Hoy día, la riqueza de las naciones no descansa sólo en la abundancia y variedad de sus recursos naturales, sino en el nivel de satisfacción que las políticas de Estado brinden a su gente. En el mundo desarrollado existen incontables ejemplos de cómo las naciones, a través de la inversión en el desarrollo integral de sus habi- 
tantes, han sido capaces de dar los saltos necesarios para insertarse en los procesos económicos vigentes en nuestro mundo globalizado. En ese sentido, ya no es un misterio que nuestro mundo se moviliza hacia una mayor interrelación de sus mercados, hacia una globalización cada vez más presente en la vida cotidiana de todos los habitantes.

Sin embargo, no podemos desconocer que entre muchas personas de nuestra región existe temor ante la sensación de riesgo e incertidumbre producida por la técnica y su capacidad manipuladora, o por la influencia creciente que la globalización parecería ejercer en forma anónima sobre las políticas públicas, especialmente en aquellas relacionadas con el ámbito económico. En este punto se plantea con fuerza uno de los dilemas cruciales: cómo establecer las relaciones de oposición y vecindad entre los procesos que algunos llaman de mundialización de las economías y el respeto a ese valor o tarea primordial del bien común al cual se deben los estados y sus acciones. Se trata de un dilema que se encuentra muy presente en América Latina. Estoy segura de que muchos de quienes ejercemos responsabilidades políticas en la región vislumbramos un sinnúmero de posibilidades en torno a la globalización, pero también comprendemos los temores que ésta ha traído consigo. Muchos la acusan de haber sido una fuente de inestabilidad, desocupación y desconcierto, provocando una sintonía de frustración social ante lo que generalmente se percibe como el resultado de modelos económicos anónimos y despersonalizados.

\section{La riqueza de las naciones descansa también en el nivel de satisfacción que las políticas de Estado brinden a su gente.}

El fenómeno descrito no sólo se ha asentado en nuestro continente. La globalización constituye un fenómeno histórico transversal que también aglutina adherentes en el mundo industrializado. Para muchos, la escasa atención prestada por diversos organismos internacionales a la crisis que aqueja actualmente a varios países de América Latina, se presenta como un síntoma preocupante de marginalidad, un efecto más de ese proceso de creciente interrelación entre las naciones. Al parecer, dichos organismos no se preocupan mayormente por lo que ocurre en nuestro continente. De hecho, durante este período de turbulencias, hemos escuchado a altas autoridades financieras internacionales insinuar que la comunidad internacional estaría acostumbrada a las crisis económicas provenientes de esta región. Más aun, hemos visto que esos mismos organismos financieros le prestan más atención a las crisis ocurridas en otros lugares del globo, cuyos problemas no son inferiores a los nuestros, pero donde los riesgos políticos que implicaría desatenderlos son mayores.

Lo paradójico de esta situación es que mientras nuestra región ha integrado a su economía gran parte de las reformas estructurales impulsadas durante los dos últimos decenios, empresa que nos ha significado una apertura sin parangones históricos, des- 
de el mundo desarrollado nos envían señales a veces contradictorias que despiertan un cierto malestar entre quienes consideramos que la globalización y el sistema de libre comercio constituyen la base para el desarrollo de nuestros pueblos. Para quienes apoyamos o adscribimos las tesis del libre comercio, para quienes pensamos que éste debe sustentarse en principios de competitividad sin exclusiones, ese tipo de medidas son muy difíciles de explicar y nos plantean dudas sobre la voluntad que existe en el mundo de avanzar hacia una globalización sin parcelamientos, hacia un mundo en el cual los principios libertarios tengan la misma validez para todos y cada uno de los bienes y servicios que circulan a diario entre los países. Por este motivo, me gustaría subrayar que en parte de las crisis económicas por las cuales atraviesa nuestro continente hay cierta responsabilidad del mundo desarrollado, puesto que nos ha transmitido sus propias crisis de convicción respecto de un modelo económico de libertades en el cual creemos y hemos apostado todas nuestras energías, pero en el cual subsisten desconfianzas y temores, especialmente de los actores económicos del mundo desarrollado.

\section{Debemos insertarnos en un esquema de creciente interrelación con un modelo económico en que \\ la persona humana sea motor y centro de sus impulsos.}

Pese a las afirmaciones señaladas, que estuvieron presentes en Guayaquil duran- te la semana pasada -donde precisamente se planteó la necesidad de buscar respuestas para enfrentar este fenómeno que nos ha traído el siglo XXI, tal como el mundo respondió con fuerza a la situación de fines de la Segunda Guerra Mundial mediante el consenso de Washington, las normas de Bretton Woods o el surgimiento de las Naciones Unidas-, veo en la globalización un espacio histórico que nuestro continente debe aprovechar. Esta no es un dogma neoliberal, sino más bien una realidad del mundo moderno. Por ese motivo, debemos dirigir nuestros esfuerzos a insertarnos en un esquema de creciente interrelación, teniendo un modelo de desarrollo económico donde la persona humana y su dignidad sean motor y centro de sus impulsos. En este proceso hay tareas y responsabilidades compartidas por parte de nuestra región y del mundo industrializado. Porque de las señales de apertura que nos envíen y transmitan los países desarrollados, dependerá la fortaleza o rapidez con que nuestro continente se articule a este nuevo sistema de relaciones económicas y cómo lo haga.

\section{LIBRE COMERCIO E INTEGRACIÓN ECONÓMICA, PUNTOS DE PARTIDA PARA EL DESARROLLO}

En segundo lugar, creemos que es importante consolidar el libre comercio entre las naciones. Sin duda, el comercio internacional se ha transformado en una de las llaves de progreso y desarrollo económico para América Latina. Muchos de nuestros países han experimentado altas 
tasas de crecimiento económico apoyadas en una apertura exterior basada en reglas claras, estables, permanentes y equitativas. Gracias a la opción que Chile tomó a favor del regionalismo abierto, durante el decenio de los noventa logró duplicar su PIB, cosa que en el pasado le llevó cincuenta años. De manera que en esta decisión de nuestro país podemos apreciar una posibilidad real de avanzar, y no sólo en términos de tasas de crecimiento, sino también en cuanto a políticas sociales. Felizmente, estas lograron reducir los niveles de pobreza a la mitad, pero nos queda una tarea bastante dura. Considerando que para reducir el nivel de pobreza de 40 a $20 \%$ se requirió una tasa significativa de crecimiento económico, disminuirlo del $20 \%$ hacia abajo será mucho más difícil.

Optamos, entonces, por el libre comercio. El tratado de libre comercio de América del Norte suscrito por Canadá, Estados Unidos y México, constituye un testimonio de cómo la eliminación de barreras económicas entre los países permite lograr un aumento sin parangones del flujo comercial y de inversiones. Dicha experiencia ha calado hondo en América Latina. Hemos visto la consolidación de un camino de desarrollo económico en un país cercano. Hemos comprobado que el libre comercio no sólo trae consigo el progreso social y económico, sino también una cultura de la propia responsabilidad anidada en torno a una visión más amplia aun y que se refiere a la cooperación como principio rector de las relaciones económicas internacionales. En el caso de nuestro país, se emprendió un programa de apertura económica unilateral que ha significado reducir gradualmente los aranceles -este año tenemos un $7 \%$ y llegaremos a $6 \%$ en el 2003- y que ha servido como modelo en nuestra región. Y durante el decenio de los noventa, dicha apertura económica derivó en una nueva forma de integración denominada regionalismo abierto, que permite combinar apertura unilateral a los mercados internacionales sin excluir un tratamiento preferencial -y por lo tanto más profundo- para otros países de la misma región.

\section{La experiencia del NAFTA ha consolidado un camino de desarrollo económico en un país cercano.}

Sin duda, América Latina no ha permanecido inmóvil durante estos años. Como creemos en una libertad de comercio sin exclusiones y fundada en una libertad de oportunidades, podemos advertir que se han realizado serios esfuerzos por avanzar hacia una mayor integración económica con el mundo. A diferencia de las doctrinas basadas en el asistencialismo, vemos en esta revalorización del libre comercio una expresión más de esa filosofía de la cooperación que busca el desarrollo y el progreso de los pueblos a través de iniciativas compartidas y horizontales, y no de carácter esencialmente vertical. Los esfuerzos en este sentido han sido variados y múltiples, algunos orientados hacia el subregionalismo y otros, más ambiciosos aun, diseñados para unir a todo el continente. Me refiero al Área de Libre Comercio de las Américas 
(ALCA), que comenzó en diciembre de 1994 durante la Cumbre de las Américas realizada en Miami.

\section{América Latina requiere cooperación para el desarrollo para insertarse con éxito en la globalización.}

En esa oportunidad, los jefes de Estado y de gobierno de las 34 democracias de la región, acordaron establecer un área de libre comercio a fin de eliminar progresivamente las barreras al comercio y a la inversión en todo el continente americano. Más tarde, durante la reunión del año pasado en Canadá, se acordó concretar este esfuerzo para el año 2005. Los principios rectores que condicionan las negociaciones del ALCA son adoptar decisiones por consenso, validar el principio de la transparencia en las negociaciones y encaminarlas por un sendero congruente con las reglas y disciplinas de la OMC. Gracias al acuerdo, en noviembre del año pasado se produjo el lanzamiento de las rondas multilaterales en Doha ${ }^{3}$. También se busca hacer del ALCA un compromiso único, pero permitiendo su coexistencia con otros acuerdos regionales y subregionales, es decir, que los países puedan negociar o aceptar las obligaciones derivadas del ALCA en forma individual o como miembros de grupos de integración subregionales. A mi juicio, el gran aporte singularizado por este esfuerzo es el hecho de que este continente haya podido cambiar su mirada al desarrollo desde una perspectiva más cooperativa. Hemos visto los beneficios que el NAFTA le ha acarreado a la economía mexicana. Sin duda, la lección más importante de este Tratado es haber reafirmado la confianza en la propia capacidad de nuestros países para sortear por sí solos la barrera del subdesarrollo.

Como lo esbocé al comienzo de esta presentación, durante las últimas décadas el Fondo Monetario Internacional, el Banco Mundial, los bancos de desarrollo regional y otras organizaciones multilaterales de crédito han contribuido con miles de millones de dólares de asistencia para Latinoamérica. Desde comienzos de los cincuenta, el Banco Mundial por sí solo otorgó préstamos por cerca de 300.000 millones de dólares a países en desarrollo, muchos de los cuales llegaron a nuestra región. Pese a este esfuerzo significativo, queda un enorme camino por recorrer hacia un desarrollo económico que sea capaz de recoger en forma oportuna y permanente las señales que emite la economía. Hoy, más que nunca, estamos frente a procesos que son esencialmente dinámicos y muy permeables a los cambios tecnológicos y científicos. América Latina requiere cooperación para el desarrollo, a fin de insertarse con el mayor éxito posible en la globalización. Esas son las señales políticas que a mi juicio deberían liderar las nuevas modalidades y condiciones de contribución financiera.

${ }^{3}$ Se refiere a la Cuarta Conferencia Ministerial de la Organización Mundial de Comercio, realizada desde el 9 al 14 de noviembre de 2001 en Doha, Qatar. 


\section{IMPORTANCIA DEL SISTEMA DEMOCRÁTICO}

La tercera sugerencia que me permito compartir con ustedes dice relación con la necesidad de consolidar institucionalmente el sistema democrático en América Latina. No podemos desconocer los efectos que la crisis actual ha generado en el desarrollo y sustentabilidad de nuestros procesos democráticos. Sin duda, a nuestro continente no le ha sido fácil avanzar en ese sentido. A veces vemos que las dificultades no surgen de una falta de convicción sobre el modelo, en torno al cual me atrevería a asegurar que existe un consenso mayoritario, sino que reflejan los intentos por profundizar nuestras propias instituciones democráticas. Porque hoy vivimos una experiencia única: hemos logrado que en todos los rincones de nuestra América Latina prevalezcan modelos democráticos como forma del ejercicio del poder. Hace algunos años, nuestro continente se hallaba sumergido en experiencias autoritarias donde se traslucía una clara falta de voluntad por encauzar procesos democráticos. Sin duda, hace quince años atrás las dificultades económicas tan serias o las crisis políticas -por qué no reconocerlo-que existen en la región, habrían tenido otra salida. Pero en la actualidad, pese a las situaciones bastante complejas que vemos hoy en día, incluso con sucesiones presidenciales -en Bolivia, muere el presidente Bánzer, asume el vicepresidente y se produce una elección cuyo resultado final dependerá de la resolución que haga el Congreso boliviano en los próximos días, y en Argentina, vemos lo que ocurre tras la renuncia del presidente de la Rúa-, todos los procesos se encauzan dentro de las normas democráticas.

\section{En todos los rincones de América Latina prevalecen modelos democráticos de ejercicio del poder.}

Cabe destacar que una parte muy sustantiva de la opinión pública mundial evalúa nuestros procesos históricos según el grado de fidelidad con las normas de convivencia democrática, y eso es muy bueno y favorable para nuestros países. Más aún, diría que el hecho de que en Chile se valore la existencia de un sistema democrático sólido y la vigencia de un estado de derecho, fue lo que nos permitió alcanzar un acuerdo de asociación con la Unión Económica Europea en abril pasado. Muchas veces nos ha preguntado por qué quince países con el desarrollo económico que tienen, con el ingreso per cápita que tienen y con un total de 372 millones de habitantes, se interesaron en negociar con nuestro país. Tal vez la razones fundamentales fueron que nuestro país optó a favor del regionalismo abierto, decidió abrirse al mundo, consolidó su sistema democrático, tiene políticas serias y no cae en populismos.

Como decía, hoy se aprecia que los países de América Latina valoran el sistema democrático y que, gracias a la acción concertada de grandes e importantes sectores de la sociedad civil, este habría alcanzado su madurez. Ciertamente, debemos seguir avanzando para que esta 
semilla de la democracia se asiente en un terreno fertilizado por instituciones sanas, transparentes e independientes de todo control arbitrario. La legitimidad de nuestra participación en la comunidad internacional transita en gran medida por la calidad de nuestro sistema jurídico y político, por la calidad y oportunidad como nuestras instituciones actúan en defensa de los derechos humanos, por la transparencia de nuestras instituciones y por el respeto con que investimos al valor de la libertad. Pese a los avances, sin embargo, estoy consciente de que a nuestro continente le resta mucho camino por recorrer en la senda hacia la consolidación de las instituciones democráticas.

\section{Enfrentamos un modelo institucional sustentado en la defensa de principios y valores que requieren una mirada más amplia y global.}

Mi reflexión también apunta al hecho de que nos enfrentamos a un modelo institucional sustentado en la defensa de principios y valores que si bien es cierto están vigentes y válidos, requieren de una nueva mirada más amplia y global. Por ese motivo, es necesario enriquecer nuestra institucionalidad con mecanismos que logren dar respuestas a las actuales inquietudes sociales. Me refiero a la importancia de la cultura, a la protección del medio ambiente o a la participación social. La gran mayoría de nuestros jóvenes desean seguridad laboral, quieren vivir en paz y esperan ver satisfechas sus necesidades de salud y previsión, pero también aspiran a lograr una calidad de vida que les permita ser felices. Y nuestra institucionalidad democrática debe ser capaz de recoger y darle forma a esas nuevas dimensiones de convivencia social.

\section{COOPERACIÓN ENTRE El Estado Y LA SOCIEDAD CIVIL}

En cuarto lugar, me parece fundamental que seamos capaces de consolidar una red de cooperación entre el Estado y la sociedad civil. La sociedad debe poner más atención en las iniciativas de participación social que han surgido en varias partes de América Latina, redoblando los esfuerzos por concretar la cooperación entre sociedad civil y agentes estatales. Comparto la percepción de que varias de nuestras constituciones establecieron la cosa pública como una tarea del Estado y no del ciudadano común, o no como una carga política compartida entre ambos actores. El efecto más legible de esta apreciación en términos políticos, es que la democracia pasa así a ser un resorte exclusivo de los gobiernos, es decir, de lo visto desde la perspectiva ciudadana, de terceras personas y no del ciudadano.

Es muy probable que este escenario no hubiese sido materia de discusión en nuestro continente hace un par de décadas, cuando el interés ciudadano por la cosa pública se relacionaba más bien con lo que podríamos llamar "alta política", o cuando los ciudadanos se involucraban en asuntos públicos en forma puntual, marginal y esporádica. Pero hoy día la 
sociedad civil ha cambiado y exige una participación real. Dicho fenómeno plantea exigencias bastante altas para quienes ejercemos responsabilidades públicas, para sus instituciones y para el mismo funcionamiento del estado de derecho, pero creo que son auspiciosas para la buena marcha y el desarrollo democrático de nuestra nación.

Sin duda, la cooperación entre el Estado y la sociedad civil constituye uno de los procesos más estimulantes para la ciencia política contemporánea. Se trata de un escenario de proyecciones políticas insospechadas y un fenómeno que recorre transversalmente todo nuestro continente. En esta última década, América Latina ha sido rica en iniciativas nacidas del tejido social y hemos sabido avanzar en la institucionalización de canales de participación ciudadana. Ciertamente, su fin último es legitimar la acción del Estado, pues detrás de ellos se esconde una voluntad viva y permanente de inserción política. Pero la participación también aporta recursos al diseño de soluciones que por su naturaleza tienen un trasfondo político. En síntesis, cuando planteo la necesidad de crear mayores espacios de colaboración entre el Estado y la sociedad civil, estoy pensando en la necesidad de aumentar la responsabilidad ciudadana en el ejercicio de las tareas estatales, a fin de lograr una mayor eficacia en el cumplimiento de ellas.

\section{Es preciso aumentar la responsabilidad ciudadana en las tareas estatales.}

\section{LA MODERNIZACIÓN DEL ESTADO}

Mi quinta sugerencia sería avanzar en las reformas del aparato estatal, a fin de que los países de América Latina puedan contar con organismos capaces de tomar decisiones adecuadas y eficientes. Tenemos, qué duda cabe, un desafío no menor. En un escenario mundial de constantes cambios, la oportunidad y calidad de las reacciones del Estado constituye un indicador cada vez más importante para medir el nivel de protección que este brinda a sus ciudadanos y a sus derechos. Y la magnitud del desafío modernizador es aun mayor cuando se trata de una región que busca consolidar su presencia internacional. Quisiera destacar que no estoy hablando de un mero ejercicio reduccionista, es decir, de achicar el tamaño del Estado a fin de lograr más eficacia en su labor, según los postulados que imperaron con fuerza hace dos décadas atrás. Me refiero más bien al hecho de que exista un Estado modelo capaz de brindar seguridad jurídica, de tutelar en forma adecuada los derechos de las personas y de dotarse de una institucionalidad dinámica y moderna, coherente con la internacionalización que actualmente se exige a nuestras economías.

Como primer elemento de modernización estatal, me parece importante contar con una institucionalidad democrática y generadora de igualdad de oportunidades. Al respecto, estoy segura de que muchos coincidirán conmigo en torno a la necesidad de tener constituciones democráticas, pues no se vislumbran experiencias modernizadoras que hayan per- 
durado en el tiempo sin que detrás de ellas exista un proceso de legitimación social. De ello dependerá en gran medida que todo el aparato institucional sea debidamente aceptado por parte de la comunidad internacional y de sus actores económicos. En segundo lugar, vinculado a la premisa anterior, se advierte la necesidad de tener instituciones fuertes y que operen con absoluta independencia entre sí. Para gran parte de la comunidad internacional, la presencia de un poder judicial independiente y que ejerce su actividad con absoluta independencia de presiones foráneas, influye en forma significativa al momento de juzgar la calidad misma de la gestión del Estado en el contexto del desenvolvimiento democrático. De hecho, el flujo de inversiones económicas es especialmente sensible al comportamiento de los poderes judiciales, siendo muy favorecido cuando éstos son eficientes y creíbles, o cuando ofrecen certidumbre y un umbral de seguridad jurídica.

Lo distintivo en este proceso de reforma o modernización del Estado no es solamente la rapidez de su reacción o la eficiencia de su gestión, sino también la calidad de sus respuestas ante los estímulos de un mundo globalizado. A modo ilustrativo, en la cartera que hoy tengo bajo mi responsabilidad se ha hecho necesario efectuar algunos ajustes para asumir lo que significa el mundo internacional, pues nos encontramos ante un mundo dinámico que plantea nuevos desafíos y exige respuestas oportunas y eficientes por parte de los estados latinoamericanos. Dichas exigencias son variadas en complejidad, pero todas apuntan a hacer de nuestros organismos estatales un instrumento complementario en los esfuerzos de desarrollo de los distintos países. Desde ese punto de vista, hoy día la principal tarea de nuestra Cancillería no es el tema de las fronteras, por ejemplo, sino la negociación de acuerdos económicos. Recién acaban de concluir con éxito las conversaciones con la Unión Europea, estamos en negociaciones bilaterales con Estados Unidos y se han efectuado cuatro rondas de negociaciones con Corea del Sur y la European Fair Trade Association (EFTA). También existe interés de Japón por iniciar nuevos procesos de negociación, como asimismo, de Singapur, Nueva Zelandia y Australia. Por otra parte, hemos participado en las rondas bilaterales de la OMC y en el proceso del ALCA. En todas las tareas de nuestra agenda vemos un esfuerzo por fortalecer el multilateralismo.

\section{Para perdurar en el tiempo, las experiencias modernizadoras exigen un proceso previo de legimitación social.}

Por otra parte, se observa una presencia activa de Chile en todos los foros políticos relacionados con los principales temas que se debaten con fuerza en el mundo de hoy. Ya tenemos el endoso de los países de América Latina para formar parte del Consejo de Seguridad de las Naciones Unidas en el año 2003. Somos el único país de América Latina que forma parte de la red de seguridad humana que se reunió hace quince días en nuestro 
país y cuya presidencia se trasladó ahora a Austria. Chile también forma parte del consejo asesor del secretario general de Naciones Unidas en el tema de intervención humanitaria, ese gran desafío que lanzó en ocasión de la Cumbre del Milenio. En algunos días más estaremos en la Conferencia de Johanesburgo sobre Medio Ambiente y vamos a ser sede del cincuentenario de la Comisión Permanente del Pacífico Sur (CPPS). Precisamente esa meta histórica de las doscientas millas alcanzada hace cincuenta años, demuestra que cuando nuestro país se propone ciertos desafíos y persevera en ellos, logra traducirlos en temas de gran relevancia para el derecho internacional.

Con esta breve reseña de algunas de las tareas que involucra la actual política exterior, podrán apreciar la necesidad de modernizar el Estado, un esfuerzo que muchos gobiernos de la región han hecho suyo y que han empezado a plasmar en acciones concretas. De más está decir lo que ha significado el esfuerzo de Chile en la reforma del poder judicial, que hoy día destaca dentro de la región como un sistema que ciertamente ha acogido los principios más dinámicos del proceso penal y que está siendo seguido con mucha atención desde muchos lugares.

\section{TRANSPARENCIA EN LAS}

FUNCIONES PÚBLICAS

La sexta sugerencia sería consolidar la transparencia en nuestras instituciones públicas, un aspecto al cual la comunidad internacional le asigna especial im- portancia. La idea de buen gobierno va ligada a conceptos como la transparencia, de manera que si un Estado no le presta suficiente atención, sus acciones se ven debilitadas y cuestionadas. Los esfuerzos que América Latina ha emprendido en este sentido persiguen trasladar tareas desde un Estado sobresaturado a otro de carácter más subsidiario. Porque la subsidariedad no es solamente un concepto económico: constituye también una forma de descentralizar, invitando a las comunidades civiles a integrarse a la red pública.

\section{La subsidiariedad no es sólo un concepto conómico sino una forma de descentralizar.}

Nuestro continente ha buscado abordar el tema de la transparencia a través de un planteamiento globalizado que integre a todas las "sociedades intermedias" posibles. Hay consenso en la necesidad de avanzar hacia una cultura que evite los riesgos de la corrupción, una de las mayores amenazas o flagelos del Estado moderno. Los esfuerzos de los países de la región han apuntado a distintos niveles, partiendo por la educación y la concientización social. En otras palabras, construyendo una red de docentes, alumnos y comunidades que participen activamente en experiencias educativas innovadoras, fomentando la participación y los valores de la convivencia dentro del aula, la escuela y la comunidad en su conjunto.

Desde otra área de acción, existen 
programas que apuntan a controlar la corrupción en las compras públicas, a diseñar e implementar una encuesta que mida las percepciones de los ciudadanos en casos específicos de corrupción, a transformar los medios de información en un canal efectivo de control social y público de los actos de los funcionarios, a mejorar las prácticas laborales de los funcionarios públicos -de hecho, en nuestro país existe un taller cuyo objetivo es establecer una alianza entre el Estado y Transparencia Internacional-, al monitoreo de las instituciones públicas, a la reforma judicial, a la creación de sistemas nacionales de integridad y a la transparencia de los procesos electorales. Todos los programas mencionados se dirigen a consolidar la transparencia, en un esfuerzo consciente por ir delegando funciones $\mathrm{y}$ tareas a una sociedad civil que madura y que reclama cada vez más participación. Esta se manifiesta de diferentes maneras, pues se trata de gérmenes de acción ciudadana que nacen y se cultivan de acuerdo a las identidades culturales de cada grupo social. Pero ciertamente, todas se encuentran unidas por un mismo objetivo, cual es el de cautelar los sistemas democráticos latinoamericanos, haciéndolos más transparentes y eficaces.

\section{LA EDUCACIÓN COMO \\ CLAVE DEL PROGRESO}

La séptima sugerencia es educar para el desarrollo. Este proceso de globalización que está, que existe, que es real, cuenta con fervientes defensores, pero también con detractores. Lo hemos visto con mucha fuerza, y desgraciadamente, en algunos casos también con violencia. Y detrás del proceso de mundialización se advierten oportunidades, pero también desafíos. Por ese motivo quisiera detenerme en la educación, un ámbito que resulta clave para la integración de América Latina en un mundo cambiante, en un sistema donde ella ha adquirido un grado de importancia tal, que ya no es posible concebirla como una más entre las tareas de un Estado moderno, sino como un pilar de su legitimidad social. La educación juega un papel clave en el avance del clima económico y político del hemisferio, en el fortalecimiento de las instituciones democráticas, en la eliminación de la pobreza, en el aumento del crecimiento económico y en el sostenimiento de los recursos naturales y de las comunidades.

\section{La educación es un pilar de la legitimidad social del Estado moderno.}

Existe conciencia regional sobre este problema. Durante la Cumbre de las Américas realizada en abril de 1998, precisamente aquí en Chile, los jefes de Estado y de gobierno suscribieron un plan de acción en el cual se declaró que la educación era la clave para el progreso de las Américas. Por otra parte, se reiteró el compromiso de la cumbre de Madrid en el sentido de lograr el acceso universal a la enseñanza primaria de calidad dentro del hemisferio, tomando la decisión de proseguir con las estrategias multilatera- 
les de educación y continuar desarrollando el financiamiento y la cooperación horizontal. También se analizó la forma de proporcionar enseñanza de nivel secundario para al menos un $75 \%$ de los jóvenes, teniendo como meta el año 2010, y de fomentar oportunidades para la superación personal de toda la sociedad a través del acceso a la enseñanza. En este contexto, bien vale la pena preguntarse por la relación que surge de inmediato entre libertad de enseñanza, cultura e identidad regional. Creo que se trata de un debate aún en vías de germinación, pero al cual le asigno una gran importancia para impulsar un modelo cultural propio que sirva de instrumento en esta senda del desarrollo y posterior fortalecimiento de la presencia internacional de América Latina.

No son pocas las voces que han lamentado y reclamado ante lo que perciben como un modelo educacional anquilosado. Algunos más, otros menos, pero en general, todos coinciden en que la buena educación es necesaria para desarrollar las capacidades productivas de una nación a fin de que esta logre insertarse con plenitud y oportunidades en un mundo cada vez más globalizado. Algunos países ya se encaminaron hacia este cambio y podemos rescatar algunas lecciones de sus experiencias educativas exitosas. Entre ellas, destaca la necesidad de fortalecer y potenciar en el nivel regional los instrumentos y herramientas que nos lleven a alcanzar el objetivo de un acceso lo más universal posible al sistema educacional. Estoy segura de que para alcanzar una paz social estable y durade- ra, sería necesario enfocar los esfuerzos en torno al principio de la igualdad de oportunidades. También me parece importante trabajar con un consenso social que haga de la educación una prioridad entre las políticas de inversión pública. De hecho, las grandes potencias tecnológicas de hoy ya transitaron y cruzaron el umbral de esa definición política. Parte de los recursos públicos que antes destinaban a ayuda social, hoy día financian inversiones en el área educacional y en nuevas tecnologías. Al observar los índices de calidad de la educación de algunos países europeos, destacan justamente aquellos que fueron capaces de dar un giro profundo en su modelo de enseñanza y que concentraron gran parte de sus recursos públicos al desarrollo de nichos de conocimientos, agrupados en torno a lo que se conoce como nueva economía.

\section{Para lograr una paz social duradera, los esfuerzos deberían centrarse en el principio de la igualdad de oportunidades.}

Desde otro punto de vista, cuando planteo la tesis de una "educación para el desarrollo", me refiero también a lograr un modelo de educación integrada donde la instrucción científica y técnica especializada se considere en función de los problemas humanos fundamentales. El compromiso de la educación no sólo constituye una tarea necesaria para el progreso económico de nuestros pueblos, sino también para su desarrollo. Tanto es así que el desafío de crear riqueza me 
parece tan relevante como el de crear mentes omnicomprensivas, amantes de valores tan disímiles y a la vez tan complementarios como la libertad y la responsabilidad. Es evidente, entonces, que las decisiones de esta naturaleza requieren de un importante consenso político y social. Pero estoy convencida de que debemos impulsar una revolución en nuestro modelo educacional. América Latina no ha sido capaz de salir de la pobreza, pero sí ha sido capaz de conquistar la libertad.

Sin duda, el tránsito desde una educación instructiva hacia otra de carácter más libertario nos demandará un esfuerzo de carácter amplio, puesto que la educación no sólo deberá satisfacer una aspiración sociocultural a veces abstracta, sino más bien buscar y recoger las expectativas, necesidades y realidades que demandan nuestros pueblos y que el mundo requiere. Creo que así contribuiremos a romper los estigmas sobre la falta de preparación de nuestro continente para afrontar en serio los desafíos de la globalización, en un mundo de tecnologías de punta extremadamente complejas. Dentro de América Latina, debemos ser capaces de avanzar en los esfuerzos que hace el mundo en materia de ciencia y tecnología. A manera de ejemplo, dada su desventaja con países como Estados Unidos en términos de la cantidad de recursos que destinan al desarrollo de la ciencia y la tecnología, la Unión Europea ha decidido realizar convenios marco a fin de invertir el 3\% de su PIB en esas materias. Una medida que viene a complementar lo que cada uno de los quince países pertenecientes a ese organismo ya está realizando en ese sentido.

\section{El desafío de crear riqueza es tan importante como el de crear mentes que defiendan valores como la libertad y la responsabilidad.}

\section{UNIDAD, DENTRO DE LA VARIEDAD}

La octava sugerencia es respetar nuestras identidades. Los 500 millones de habitantes de Latinoamérica tenemos notables diferencias culturales y sociales, pero tenemos también una matriz común formada por una tradición Iberoamericana, dos idiomas de una misma raíz, una misma religión, hábitos y costumbres similares y una estructura institucional parecida. Asimismo, nuestra base social está compuesta de una inmensa población mestiza e indígena, un importante componente negro mayoritario en algunos países, una vieja clase descendiente de los colonizadores que aún conserva posiciones relevantes y una gran cantidad de representantes de origen europeo en nuestra clase media. Nuestra cultura se ha caracterizado desde sus albores, desde cuando el hombre comenzó a dar pie a lo que el jurista alemán Savigny asoció al espíritu del pueblo, por ser transportadora de ideas, de mensajes de los individuos a los colectivos sociales. ¿Quién podría negar el gran aporte que Venezuela dio a Chile, enviándonos a un Andrés Bello, o bien al 
continente, con el libertador Simón Bolívar? ¿No fue acaso Sarmiento quien trazó las primeras líneas del sistema educativo chileno? En nuestro continente existen varios ejemplos como esos, donde se percibe a la persona que trajo consigo la cultura, pero también al país de origen de esa persona. Desde este punto de vista, la cultura es y ha sido siempre un puente de comunicación entre los pueblos de América Latina. Se trata, pues, de que nuestras identidades han contribuido a formar otras identidades nacionales, a traer el progreso a los pueblos y a derrotar el silencio y los riesgos de distanciamiento que trae aparejados el localismo excesivo.

\section{La cultura siempre ha sido puente de comunicación entre los pueblos de América Latina.}

América Latina es rica en variedad, y estoy segura de que eso debemos transmitirlo al resto del mundo. Somos un continente amante de la paz, una paz construida en el respeto de nuestras propias variedades, en la libertad de su ejercicio y en la propiedad de su valoración. Nadie pone en duda el carácter multicultural del Caribe anglosajón, una cantera de expresiones artísticas, diálogos culturales y encuentros de lenguajes provenientes de distintos rincones del mundo. De la misma manera, destacan los valores de tolerancia y de libertad en los cuales se desarrollan esas sociedades. Se trata tan sólo de un ejemplo ilustrativo de la riqueza e importancia que experiencias como esas tienen para un mundo cada día más interrelacionado.

Sin embargo, tampoco debemos descuidar los temores que en gran parte de nuestro continente genera esta apertura mundial sin parangones históricos. Para muchos, el mundo se ha vuelto amenazante, impersonal e insensible ante esa variedad. Existe resistencia, pues hay temores que nacen de una sensación de inseguridad frente a lo que pueda pasarnos en nuestras vidas cotidianas, especialmente frente al avance irreductible de la globalización. De hecho, muchos la asocian a una aplanadora que gusta de la unidad, pero no de la variedad. Nada más rico que la variedad o, mejor dicho, nada más apasionante que una cultura globalizada. La variedad en sí misma es plástica, dinámica, fuente de insospechadas posibilidades, recogedora de procesos vivos y a la vez cauteladora de las tradiciones culturales más profundas de una nación. Testimonio de ella son nuestros insignes poetas Premio Nobel, Gabriela Mistral y Pablo Neruda. ¿Cómo desconocer la vocación americanista de Neruda, cómo evitar recordarlo si no es a través de su cántico a Macchu Picchu? ¿Cómo olvidarnos de esas palabras pronunciadas por nuestra Gabriela Mistral cuando recibió el Premio Nobel de Literatura en el año 1945?: "Soy en este momento la voz directa de los poetas de mi raza y la indirecta de las muy nobles lenguas española y portuguesa".

Unidad en la variedad, o bien, retomando una idea expresada al comienzo, identidades dentro de una sola identidad. Esa pareciera ser la posibilidad a que nos 
invita la integración de esta visión de la cultura en un contexto internacional de creciente internacionalización.

\section{LA PROTECCIÓN DEL MEDIO AMBIENTE}

La novena sugerencia tiene que ver con la búsqueda de una mirada hacia el desarrollo sustentable: América Latina en un ecosistema globalizado. Me refiero a la necesidad de impulsar un modelo de desarrollo perdurable e impregnado de un contrato generacional entre quienes tenemos responsabilidades y quienes nos sucederán en el futuro. Estoy hablando, en definitiva, de evitar el riesgo de buscar compromisos de primera clase con las actuales generaciones y de segunda categoría con aquellas que vendrán en el futuro. De esa manera, los compromisos sobre el desarrollo sustentable pierden fuerza moral y legitimidad en el concierto internacional.

\section{Subyace un prejuicio fundamentalista acerca de las funciones del Estado y de los actores privados en la protección del medio ambiente.}

Uno de los debates ambientales que está penetrando con mayor fuerza en los círculos académicos y políticos contemporáneos, se refiere al papel que le corresponde a un Estado moderno y subsidiario en el cuidado de su patrimonio ambiental. Lo cierto es que la opinión pública de nuestros países percibe que las políticas públicas ambientales del continente no han sabido aglutinar ni amalgamar en forma coherente un arquetipo de estrategia ambiental que recoja el modelo de sociedad libre, pero sin embargo capaz de allegar una visión conciliadora entre un espacio de globalización y una sociedad civil con creciente madurez ambiental, o entre un medio ambiente tolerable socialmente y una economía de libre mercado. En el fondo, creo que subyace un prejuicio fundamentalista en torno a las funciones que le corresponden al Estado y a los actores privados en la protección del medio ambiente. Porque estoy convencida de que la conservación ambiental no sólo es una tarea del Estado, aunque tampoco puede excluírselo de este empeño. Lo que debemos asumir es que la única manera de afrontar los desafíos cada vez más complejos en este ámbito es a través de una visión integradora y no excluyente de las competencias ambientales. Muchos estados desarrollados tienen contemplada la protección como una tarea prioritaria. Más aun, en algunos países esta tarea ha adquirido tal grado de importancia, que no sólo es entendida como una más dentro del conjunto de sus obligaciones, sino que forma parte del abanico de tareas que contribuyen a su legitimación. En otras palabras, el Estado pierde en confianza y legitimación cuando su labor en materia de protección ambiental es deficitaria. Basta mirar lo que sucederá en septiembre próximo durante la Cumbre de Desarrollo Sustentable de Johanesburgo, para comprender hasta qué punto las políticas públicas 
ambientales han impregnado la labor de los Estados desarrollados.

Sin embargo, el debate también debe incluir la responsabilidad ciudadana en la formulación y logro de metas ambientales, que día a día crece en significación. La política y la ciencia se han visto obligadas a reflexionar en torno a la percepción de que nos encontramos frente a una naturaleza vulnerable, dentro de la cual la acción humana ha demostrado tener un tremendo poder. En algunos países desarrollados, los ciudadanos están siendo forzados a participar activamente en decisiones de carácter ambiental. Se trata, justamente, de aquellos donde la protección ambiental se concibió al principio como una tarea del Estado hacia sus ciudadanos. Lo interesante, sin embargo, es que este debate no coloca a los ciudadanos y al Estado en una postura asimétrica, sino al contrario, en un plano de complementariedad y cooperación. Y esta doctrina ha comenzado a impregnar el discurso político de los países de nuestra región.

La calidad de las acciones públicas a favor de la protección ambiental juega un papel cada vez más relevante en la percepción que se tiene internacionalmente sobre un determinado Estado. Es más, hoy día el grado de resguardo ambiental se utiliza como un indicador validado en el análisis internacional. No debemos menospreciar la creciente atención que el mundo desarrollado le asigna a cada una de las reuniones internacionales abocadas a cuestiones de índole ambiental. Estamos ante problemas de cambio climático, de desertificación, o bien ante el transporte de sustancias peligrosas. En todas ellas se aprecia una decisión por ir gestando voluntades hacia un desarrollo más sustentable.

\section{Para legar un país limpio a las próximas generaciones se necesita un contrato social entre Estado y ciudadanía.}

No es un misterio que la generalidad de los habitantes de nuestro continente miran acuciosamente al Estado cuando se buscan responsables por las distintas formas de contaminación ambiental. Al respecto, recordemos que la gran mayoría de las constituciones -comenzando con la de Chile, por cierto- han alentado esa percepción pública de Estado negligente, pues lo que hicieron fue "estatizar" al medio ambiente como una tarea del Estado y no del ciudadano común o, dicho de otra manera, no como una carga legal compartida. Ello no debería sorprendernos, pues en nuestros órdenes constitucionales predominan los derechos, pero no así las obligaciones. Sin embargo, lo dramático de esa percepción ciudadana es que está visto que el Estado es incapaz de resolver los problemas ambientales por sí solo. De manera que si queremos legar un país limpio a las próximas generaciones, se requiere la urgente concurrencia de toda la sociedad, un contrato social entre el Estado y la ciudadanía. Para esos efectos, debemos desmitificar algunos presupuestos básicos que han entorpecido el avance hacia un modelo institucional menos tensionante en su relación con 
el medio ambiente. Me refiero, por ejemplo, al hecho de si es deber del Estado garantizar medios ambientales libres de contaminación.

\section{Tanto Estado como sea necesario y tan poco Estado como sea posible.}

América Latina posee un patrimonio ambiental extraordinariamente rico y variado. El mundo eso lo sabe, y nos juzga en cada acción o inacción que tengamos en este ámbito. Me parece que debemos esforzarnos por gestar al interior de nuestro continente una discusión que nos permita diseñar un modelo de desarrollo sustentable coherente con las capacidades y vulnerabilidades propias de nuestras pertenencias ambientales. Sin duda, la inserción internacional pasa también por mostrar un compromiso con el entorno. Creemos que para alcanzar un consenso social sobre el tema, el Estado debe guiar su accionar buscando dar tanta protección al medio ambiente como sea necesario, y a su vez, tan poca como le sea posible. Es decir, tanto Estado como sea necesario y tan poco Estado como sea posible. Con ello, no quiero eludir el debate sobre las capacidades, deberes y posibilidades que deben asumir los diferentes actores en la protección ambiental. Se trata, más bien, de respetar el valor sublime de la libertad del hombre.

\section{ENFRENTANDO AL MUNDO \\ CON UNA VOZ COMÚN}

La décima sugerencia es un gran desafío: cómo insertar un sentido regionalista a un mundo multipolar. Sin duda, los países que damos vida a este continente no somos solamente algunas casas dispersas en un mismo barrio. La riqueza y profundidad de nuestros compromisos delatan una relación tal, que me atrevería a describirlas como de casas vecinas, cada una con su identidad y tamaño propio, pero todas ideadas por un mismo arquitecto. Si bien es cierto que nuestros países vivencian los mismos fenómenos con distinta intensidad, creo que ninguna otra región del mundo está tan unida en torno a valores comunes como América Latina. En nuestro continente existe un fuerte sentimiento de pertenencia a Latinoamérica y, desde afuera, generalmente se nos mira con un mismo prisma. Ello nos brinda la posibilidad de construir conceptos ideados en nuestra propia cantera cultural. Dicha similitud valórica nos ha permitido enfrentar desafíos globales con un sentido de unidad que es destacable en nuestro diálogo como continente con la Unión Europea, en las labores y tareas emprendidas por el Grupo de Río y que se refleja al articular posiciones en diversas negociaciones internacionales. En fin, nuestra región ha sido capaz de modular una voz común en las más distintas expresiones de política exterior.

Tal como América Latina ha sabido encontrarse en la variedad, hemos sabido respetar nuestras propias individualidades, muchas de las cuales tienen un 
sentido de carácter regional. Así, por ejemplo, estoy segura de que la inserción de Chile en la APEC -del cual nuestro país será sede en 2004- servirá de puente para que a través de nuestra participación, junto con la que tienen Perú y México, seamos capaces de brindar señales regionales, no unilaterales.

\section{Nuestra similitud valórica nos ha permitido enfrentar desafíos globales con sentido de unidad.}

Por otra parte, nuestra integración al bloque del Asia Pacífico contribuye a enriquecer el diálogo entre nuestra nación y los países de la Cuenca del Pacífico. También se nos valora por el alto grado de consenso internacional que los países de la región reflejan en el mundo entero. En ese sentido, estoy segura de que el acuerdo recién suscrito con la Unión Europea, servirá de nexo entre nuestra región y Europa. El hecho de que tanto México como Chile tengan un acuerdo con la Unión Europea debería ser un fuerte estímulo para impulsar un fuerte diálogo birregional durante el próximo encuentro de jefes de Estado y de gobierno de la Unión Europea, América Latina y el Caribe, que se realizará en México en 2004, precisamente en la búsqueda de un mundo multipolar. No podría ser distinto. Como lo dijo el filósofo español Ortega y Gasset, los países son ellos y sus circunstancias, es decir, su entorno.
Para terminar, estoy convencida de que América Latina es y debe ser capaz de avanzar en la construcción de ideas de carácter regionalista, pues no queremos un mundo administrado lejos de nosotros y donde otros tomen las decisiones por nosotros. Aspiramos a formar parte de un mundo de identidades, no de un sistema donde existan identidades de primera y de segunda clase. Por ende, debemos atrevernos a construir visiones comunes y regionales en temas globales, a fin de enfrentar con mayores posibilidades de éxito los desafíos de la globalización en un continente integrado al mundo y con justicia social y equidad. Creemos que la división entre globalizadores y globalizados no puede pasar por nuestro continente y ello exige nuestra participación activa en las definiciones que a nuestro juicio deberían darse en el mundo ante las nuevas amenazas. No cabe duda de que la volatibilidad de los mercados financieros y las crisis económicas que han azotado tan fuertemente a nuestra región, hacen necesario e imprescindible que saquemos una voz común al momento de definir temas como el papel de las Naciones Unidas, por ejemplo, o las normas posteriores al acuerdo de Bretton Woods. Debemos estar presentes, pues aspiramos a formar parte de un mundo de identidades que incluya a la nuestra de América Latina, respetando dentro de ella las identidades culturales de cada uno de nosotros. 